\title{
Generating Art in Symbiotic Systems
}

\author{
SHARON IRISH \\ Research Affiliate, School of Information Sciences \\ University of Illinois, Urbana-Champaign, USA
}

\begin{abstract}
This essay reviews the book by Francesca Franco, Generative Systems Art: The Work of Ernest Edmonds (London: Routledge, 2018). This illustrated monograph discusses the primarily computer-generated work of Ernest Edmonds (b. 1942) in the context of twentieth-century art in Europe. Franco provides relevant technological history as she analyzes Edmonds' paintings and interactive and digital projects, often created in collaboration. This book is a significant contribution to the history of computer art in which Franco affirms Edmonds' focus on 'the human's way of working."
\end{abstract}

Francesca Franco's well-illustrated monograph, Generative Systems Art: The Work of Ernest Edmonds, contributes significantly to understanding art in the U.K. in the latter half of the $20^{\text {th }}$ century, and its connections to other disciplines and locales. While Franco's focus on Edmonds bridges many art historical gaps in knowledge about Edmonds and his generation of artists in the U.K. (including Roy Ascott, Stroud Cornock, Edward Ihnatowicz, the Systems Group [started by Malcom Hughes and Jeffrey Steele in 1969], and Stephen Willats), the book also links developments in computer technologies to art-making. As Charlie Gere notes in the Foreword, these "artists were fully engaged in questions of mathematics, science, technology and code," thereby refuting the two cultures demarcated by C. P. Snow. [1] The 2008 edited volume, White Heat Cold Logic: British Computer Art 1960-1980, whetted the appetite for more in-depth studies of this topic and Franco's volume usefully explores this material. [2]

\section{The Career of Ernest Edmonds}

Franco traces the career of Ernest Edmonds chronologically from his early formal training in mathematics at Leicester University, through doctoral studies in logic at Nottingham University, and his leadership in academic, computing, and art circles up through 2014. [3] Focusing on ways in which constructivism was linked to generative and interactive art, as well as connections between computer-based art and systems, Franco broadens our understanding of this vibrant time period, both technologically and artistically. She uses Margaret Boden and Edmonds' 2009 definition of generative art as a starting point: "“wherein the artwork results from some computer program being left to run by itself, with minimal or zero influence from a human being." [4] Much of the book examines this definition's assumptions, though, given that human beings and computer programs were and are intertwined. Franco notes that Edmonds" "works presented 
challenges that helped and encouraged the development of new technologies and methods, making his art practice and his research in technology a persistent mutual relationship that echoes that of a symbiotic system."

Franco's attention to Edmonds' milieu reveals little-known influences and practices at midcentury in the UK, from the theories and art of Charles Biederman to concrete poetry, from sculptors Naum Gabo and Antoine Pevsner to the circle of London Constructivists. What Franco's scholarship clarifies is the continuum in art of this time and place between traditional materials like paint and wood and human-machine creations.

Edmonds' "Nineteen," created between 1967-69, summed up his abstract explorations of that decade; in searching on Leicester's campus for a way to spray paint the twenty squares in that gridded composition, Edmonds met sculptor Stroud Cornock, who became an important collaborator. Edmonds started to program computers in 1967 and realized that these machines could not only help him solve logic problems but also compositional challenges he faced in "Nineteen." Edmonds' relationships with artists in the Systems Group and with Constructivists deepened in the 1970s, as Franco recounts, and Edmonds realized that he could use "a system as a medium to make art, including both static and interactive forms."

Edmonds' interest in systems theory was complemented by his exploration of audience interaction and human communication systems. Franco discusses four artists who delved into similar though independent investigations during this time: Malcolm Hughes; Edward Ihnatowicz; Roy Ascott; and Stephen Willats. Franco quotes Edmonds on his conversations with the older Ihnatowicz when they considered "issues that are sometimes seen as artificial intelligence subjects or cognitive science subjects which turned out to be important to art, for example the relationship between touching and perceiving, the way in which, by acting, we affect what we perceive...." This cybernetic idea - the intertwining of the perceiver and the effects of perceiving on further perception - informs much of the book because of Edmonds' fascination with audience responses to his art. Edmonds' works in the early 2000s "learned": the works changed over time in response to interactions with viewers. This adaptability reflected the influence of Ihnatowicz and well as experiments by Edmonds and Cornock in the 1970s.

Franco tells about Edmonds' contributions in the context of computer history, including the increasing availability of personal computers, graphical interfaces, and the World Wide Web. Yet the technological history is only part of the story. The author focuses on themes in Edmonds' art - structure, interaction, time, and color - and how computing assisted his artistic creations, which integrated those concepts: "By...realizing a work directly from the computer, he was able to explore colour, structure and time with no restrictions on length" and without repetition, Franco explains.

Edmonds continued to paint and draw while he built hardware and conceptualized networks in the mid-1970s. For his two-dimensional compositions, he created strict rules that Franco describes as "procedural coding work." His frequent discussions in the 1980s with sculptor and painter, Kenneth Martin, "“pointed toward software art'," according to Edmonds. He posited that software was "a medium that could be used as an aid to human creativity." 
In the 1990s, Edmonds' love of music, his connections among other artists, and changes in technology fostered work that integrated sound into his projects. Some of these complicated performances involved musicians who played next to programmed video projections, which determined what notes the musicians played and for how long. Franco quotes a 1990 lecture by Edmonds: "The man-made spaces in which we live and work are no longer defined just by bricks or concrete: information technology, computers and communication systems, is [sic] increasingly providing new ways of defining space."

Edmonds responded to new technological developments, which, in turn, he adapted to his artistic requirements, including new possibilities for audience engagement using movement sensors.

In 2002, he relocated to Sydney, Australia, where he continued his collaborative work. Linda Candy and Edmonds' Creativity and Cognition Studios, which they co-founded in 1993, teamed up with the Powerhouse Museum in Sydney on an initiative called "Beta space" to experiment with interactive art. This living laboratory allowed artists to show an almost-finished work and get feedback from the public to refine it. In 2006, Edmonds displayed a composition ("Tango Tangle") in a public space, Federation Square in Melbourne, which responded to sounds picked up around the square. Edmonds aimed to create "'open systems that develop and change sometimes directly sometimes only subtly or much later in accordance with the interaction with the environment." The process here was more important than the final product.

Edmonds continued to alternate between screen-based work and painted surfaces. Franco compares two works by Edmonds, separated by 34 years ("Fifty Two," an acrylic painting of 1980 and "Four Shaped Forms," a four-panel acrylic of 2014). Both of these works were "concerned with the organization and structure of surfaces and colors," according to Franco. She carefully contrasts the composition, the color selection process, the paint application, and relationships to other work by Edmonds. Significant to both works was Edmonds' belief that constraining artistic choices made for more powerful work. Franco notes: "A painting such as 'Fifty Two' - which was created without the aid of a computer but whose products were strongly inspired by computer programming - paved the way to Edmonds' later explorations in structure as they evolved into time-based art."

\section{“The Human's Way of Working”}

Following this analysis, Franco then describes the scientific and technological developments that Edmonds forwarded in his art practice, focusing on "the human's way of working." Edmonds' contributions to human-computer interaction include: iterative software design; adaptable user interfaces; and user interface architectures. Out of Edmonds' research came the realization "that interacting with a computer, even by programming it, could stimulate one's thinking.... Edmonds saw AI [artificial intelligence] as an assistant to human thinking, helping the human be more creative, rather than as a replacement for the human." Edmonds remains committed to research that enhances creativity rather than building autonomous systems.

Every reviewer, it seems, wants the book they are reviewing to be other than it is. This book, for me, is no exception to that desire. I welcome the excellent content, but I want more, more about Edmonds and about other artists: a discussion, for instance, of Edmonds' 1971-72 collaboration on "Rover" with Cornock would have provided a further vantage point on these two artists' productive joint research on interactivity with analogue means. [5] Edmonds' ambitious 
distributed interactive work, "Cities Tango: Between Belfast and Sydney" (2009), would have benefited from comparisons to other contemporary artwork, such as "The Maraya Project" (200713) by Glen Lowry, M. Simon Levin, and Henry Tsang, developed between Vancouver and Dubai. Regarding the content that is included, Franco assumes that the reader knows the significance of the 1968 "Cybernetic Serendipity" exhibit in London and the meaning of "restricted languages," to name two lacunae.

I was frustrated with the book's organization and style. The prose is serviceable but not elegant: Franco's frequent use of passive voice and repetitions indicate the need for further editing. With thematic analyses woven in with chronological treatment, the index is a crucial tool but, unfortunately, it was badly done. (George Mallen is discussed in the text but not listed; Stephen Willats has incomplete entries; the exhibit, "Cybernetic Serendipity," and the Seeheim model are mentioned, but not indexed, for example.) The captions for the images should provide dimensions and media.

What Franco capably does in this book is hard to accomplish: it is no small undertaking to assimilate Edmonds' substantial documentation, archival material at the Victoria and Albert Museum, one-on-one interviews with an extremely busy artist over four years, and secondary literature related to computer technology and twentieth-century art, among other disciplines. Further, Franco for the most part admirably balances technical information with art history in order to appeal to the general reader. Now that she has completed this important book, I look forward to further syntheses and insights about this and related material by this active and thoughtful scholar.

\section{ENDNOTES}

1. C.P. Snow, The Two Cultures and the Scientific Revolution [The Rede Lecture, 1959] (New York: Cambridge University Press, 1961).

2. P. Brown, C. Gere, N. Lambert, and C. Mason, eds., White Heat Cold Logic: British Computer Art 1960-1980 (Cambridge, MA: The MIT Press, 2008).

3. In 2017, Edmonds received both the Lifetime Achievement Award in Digital Art from the Association for Computing Machinery's Special Interest Group on Computer Graphics and Interactive Techniques (ACM SIGGRAPH) https://www.siggraph.org//participate/awards/2017art-award-ernest-edmonds and the Lifetime Practice Award in Computer-Human Interaction from ACM's Special Interest Group on Computer-Human Interaction (ACM SIGCHI) https://sigchi.org/awards/sigchi-award-recipients/2017-sigchi-awards/.

4. M. Boden and E. Edmonds, "What is Generative Art?," Digital Creativity 20:1-2(2009), 32.

5. S. Cornock, "The Interactive Art System," in Ideas Before Their Time: Connecting the Past and Present in Computer Art, N. Lambert, J. Gardiner and F. Franco, eds. (London: British Computer Society, 2010). http://www.stroudcornock.com/CAT\%202010\%20Cornock.pdf For more images see: http://www.stroudcornock.com/interactiveimages.html\#Rover-08.jpg 
6. A. M. W. Jim, "The Maraya Project: Research-Creation, Inter-reference and the Worlding of Asian Cities," Third Text 28:1(2014), 15-31.

\section{AUTHOR BIO}

Sharon Irish is the author of the forthcoming book, Stephen Willats and the Social Function of Art: Experiments in Cybernetics and Society (Bloomsbury, 2019). As a project coordinator at the School of Information Sciences at the University of Illinois, Urbana-Champaign, she has coauthored articles on community informatics and digital literacy. She serves as an Advisory Editor for Technology and Culture, the quarterly of the Society for the History of Technology (SHOT). sharonirish.org 